\title{
Translation of Names in Consumer-oriented Texts: In-flight Magazines Articles as a Case Study
}

\author{
Alhanouf Alrumayh $1 \mathrm{D}$ \\ PhD Researcher, University of Leeds, United Kingdom; Lecturer of Translation Studies, Majmaah University, Saudi Arabia
}

$\square$ Corresponding Author: Alhanouf Alrumayh, E-mail: mlaal@leeds.ac.uk

\section{ARTICLE INFORMATION}

Received: January 02, 2021

Accepted: February 22, 2021

Volume: 4

Issue: 2

DOI: $10.32996 /$ ijllt.2021.4.2.19

\section{KEYWORDS}

Proper names, cultural translation, consumer-oriented texts, in-flight magazines

\section{ABSTRACT}

This study aims to explore and investigate the procedures that are currently used in translating proper nouns within the area of consumer-oriented texts. The paper contributes to the development of the understanding of translation involving the English-Arabic language pair, with a particular look at differences in their cultural elements in a selection of articles that are taken from in-flight magazines of Gulf region airlines. Vermeer's model of translation operations for rendering proper names (2003) is adopted to this study while the data is arranged according to Newmark's categorization of proper names (1988). Findings show that substitution/transliteration is the most frequent translation procedure in the translation of proper names in consumer-oriented texts.

\section{Introduction}

The translation of proper names can be one of the most challenging translation decisions as it is not always the case that proper names are mere labels for identification. Many proper names have some sort of meaning that should be taking in consideration to avoid any negative consequences in translation. Thus, exploring this noun category will reveal current translation practices and identify the most problematic issues that might lead to misunderstanding especially when it comes to rendition between two relatively remote cultures.

The majority of in-flight magazines in Gulf airlines are in two languages, Arabic and English, which raises the question of what kind of translation mechanism has been used. In general, culture-based context is one of the most significant areas of current discussion in translation studies. Translation varies between relying totally on the source culture to depending mainly on the target culture. Moreover, in the case of Gulf in-flight magazines we are not initially sure about the language of the source text. Both the ST and TT have been written in such a way that it is impossible decide which is which and the marketing section of these in-flight magazine companies would prefer to keep this information confidential. Therefore, the aim of this paper is to explore the current usage of translating proper names in in-flight magazines in Gulf airlines within English-Arabic language pair based on Vermeer's model for the translation operations of proper names (2003), after the proper names in the data are classified under Newmark's (1988) categorization of proper names.

\section{2- Literature review}

Articles in inflight magazines, as culturally bound texts, contain numerous proper names such as the names of persons, places, or specific things, involving the use of many different procedures in translating them. The question of how proper names are to be translated is a controversial one among translation scholars and researchers. Christina Nord states that the common belief that proper names are untranslatable is rather a mis-perception, because when we look at translated texts, we "find that translators do all sorts of things with proper names" (2003, p.182). Nord adds that "translators do not always use the same techniques with all the proper names of a particular text they are translating" (ibid). This suggests the wide range of procedures that is adopted not only in literary texts but also in non-literary ones as well, even though literary genres allow more freedom and creativity in

K C AL-KINDI CENTER R D FOR RESEARCH AND R D DEVELOPMENT Your gateway to world-class research

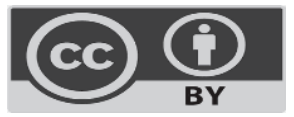

Published by Al-Kindi Center for Research and Development. Copyright (c) the author(s). This open access article is distributed under a Creative Commons Attribution (CC-BY) 4.0 license 
dealing with proper names. Nord concludes that proper names are indeed translated, if we regard 'translation' as a process of linguistic and/or cultural transfer (ibid, 183).

Newmark (1988) divides proper names in respect of translation into three categories: people's name, names of objects and geographical terms (p. 214-216). He holds that people's names should, as a rule, not be translated when these names have no specific connotation in the text. However, Newmark adds some exceptions such as names of well-known saints, monarchs, and popes, which are typically used in the translated form in the TL (ibid, p.214). As for the names of objects, such as the names of trademarks, brands or proprietaries, Newmark states that these should be transliterated along with 'a classifier' if the name is not likely to be recognized by the TL readership (ibid, p.216). Thus, 'Tesco' may be translated into Arabic as سلسة المتاجر الغذائية البريطانية تيسكو (Lit: 'British grocery chain Tesco'). Regarding his last category, geographical terms, Newmark insists that the translator must be up to date by checking all terms in the most recent trusted geographical resources. He also notes that the translator should respect a country's wish to determine its own names for its own geographical and political features (ibid). One common example involving Arabic and English is the translation of the famous sacred city مكة, where the official spelling adopted by the Saudi Arabian government is 'Makkah', but many translators fail to follow this and use 'Mecca' or 'Meccha' instead.

Dickins et al. believe that, in any culturally specific text, transliteration is the commonest way of translating names (2017, p.42). They consider problems in transliterating Arabic names, as not all Arabic letters or sounds have clear correspondents in English. They note that there are many standard transliteration systems for Arabic, but they are usually restricted to academic texts. Dickins et al. also mention that the translator should be aware of different transliteration-type equivalents in English that some Arabic names might have (ibid). Thus 'Muhammed' is commonly used for محمد in many parts of the Middle East, while elsewhere 'Mohammed' may be the more standard form. Dickins et al. note that some Arabic proper names have standard indigenous English equivalences, which are not considered transliterations (ibid). These include names of cities and countries such as 'Cairo' for مصر and 'Egypt' for القاهرة The translator would generally expect to use these equivalents whenever available except for rare restricted reasons related to the context (e.g. where transliteration is needed to convey the meaning in the TL text).

Hermans (1988, p. 13-14) presents four procedures for translating names. These are similar to what previous scholars have suggested. Pym (2004, p.92) holds onto the idea that proper names should not be translated but rather transliterated. We can conclude that translating names represents a real challenge for both professional and novice translators; therefore, such names merit attention from researchers and scholars in translation studies. Translators must be familiar with the culture of both the source and target languages, since awareness of these culture-bound names can lead to the most appropriate translation procedure.

\section{3- Methodology}

The corpus of the study consists of six bilingual in-flight magazines produced by Gulf airlines companies in English and Arabic, namely Oman Air from Oman, Gulf Air from Bahrain, Fly Nas from Saudi Arabia, Qatar Airways from Qatar, Air Arabia from United Arab Emirates and Jazeera Airways from Kuwait. Two issues were selected from each airline's magazine over a time period of six months, giving a total of 40 magazine articles (July 2017 to December 2017). These in-flight magazines are available free of charge to help passengers pass the time onboard on flights. The main contents are usually articles related to the tourism industry.

After checking the data preliminarily, we can say that the most frequent way of translating names in general is by transliterating, which is not surprising at all. However, the analysis of this section will divide the names according to Newmark's (1988) categorization of proper names, i.e. people's names, names of objects and geographical terms. To identify the translation techniques used, Vermeer's model for the translation operations of proper names (2003) will be adopted. I will also consider whether any standard transliteration system is used or whether an ad-hoc approach is adopted in translating names from English to Arabic and vice versa since the two languages have different writing systems (Dickins et al., 2017, p.42).

In his article Proper names in translation Albert Peter Vermes (2003) has demonstrated that proper names are not easy to translate. His view is in contrast to commonly held views that translating proper names is merely related to the problem of delivering the meaning of these names in the ST. Vermes surveyed the treatment of proper names in translation based on the assumption that translation is a special form of communication (ibid). Although Vermes bases his analysis on relevance theory, his views accord with functionalist scholars in translation studies, who consider the translation process as an act of communication and tend to understand the meaning of a text in terms of the function of context (Schaffner, 2011, p.115).

Vermes states that there are four main translation operations used in rendering proper names that aim at bridging the gap between the ST and the TT by producing the closest interpretive resemblance possible (Vermes, 2003, p.93). The first operation is 'transference', which refers to the process where the translator uses the ST version of the proper name without applying any 
changes in the TT (ibid). Note that the term is previously used by Newmark to describe "the process of transferring a SL word to a TL text as a translation procedure" (1988, p. 81). An example of this operation would be the rendition of 'Beach Culture WLL' in Arabic as 'Beach Culture WLL مؤسسة' without following the writing system of the TL. Newmark notes that transference works and is generally accepted in languages such as English and French which have the same graphological systems, but he also believes that transliteration can be extended to include the conversion of material between different alphabets as Russian and Arabic (ibid). Vermes, by contrast, includes transliteration under the category of 'substitution' (to be discussed immediately below). The present analysis will use the categorization of Vermes's model.

The second translation operation for proper names recognized by Vermes is 'substitution', which means using the conventional correspondent of the SL noun in the TL (Vermes, 2003, p.93). It can be found widely under Newmark's category of geographical terms, as in 'Riyadh' الرياض and 'England' إنجلترا. The translator here has no real choice but to use the conventional TL terms. Vermes includes 'transliteration' under 'substitution' because of their closeness. Transliteration refers to a situation where the ST proper noun is transcribed according to the pronunciation and the morphology of the target language (Fernandes 2006, p.51). Because of the different graphology of English and Arabic, and the fact that most proper Arabic nouns do not have standard English equivalents, and vice versa, most proper names would fall under this category. For instance, 'Bill Clinton' becomes يز يد بن عبد الملك would be transliterated in English as 'Yazid bin Abdul Malik'.

The third translation operation for proper names recognized by Vermes is 'translation proper', which is usually used when the translator gives the literal meaning of a noun in the TT (Vermes, 2003, p. 93). Newmark refers to this as "rendering the meaning of a text into another language in the way that the author intended the text" $(1988$, p.5). Under this process, the translator can use translation to bring the literal meaning of a noun or part of it into the TT if the name acquires a meaning. An example of full translation of a proper name is 'The Red Sea' translated as البحر الأحمر. The name here has reproduced the connotation of the ST term in the TT because it has a specific connotation. Rendering part of the noun, on the other hand, is used as in 'Richard the Lionheart' which is translated as ريتشارد قلب الأسد. 'Richard' has been transliterated while 'the Lionheart' is translated to deliver the connotative meaning.

The last operation is 'modification', which is the least common way of rendering the proper name. It is based on finding a substitute in the TT for the ST term. This substitute noun should be partly related to the one used in the ST either by convention or logic (Vermes, 2003, p. 94). In other words, the TT proper noun is changed on the basis of logic or convention to a TT form that is unrelated or only related partially to the original proper noun. Thus, it makes a crucial alteration to the form and implications of the ST proper noun. Vermes also clarifies that modification is a rather general procedure that can incorporate other sub-procedures such as omission, addition and generalisation. A variety of examples illustrate this process. For instance, 'Brixton, London' is rendered as حي بر يكستون في مدينة لندن ('the quarter of Brixton in the city of London'), where the underlined words are additions to these geographical names. The purpose of the addition is to clarify to the TT audience assuming that this British neighbourhood name would be an unrecognisable term to them. Another example is when the translator uses a superordinate noun for a more specific one (hyperonym for hyponym) - a procedure known as generalization. An example is the translation of 'Happiness retreat' as السعادة [lit: Happiness resort]. 'Retreat' here has been replaced by superordinate noun منتجع 'resort' as there is no direct equivalent. The TT form keeps the core of the ST meaning.

The best way to give an overall view of Vermes's model of translation operations is through applying one example that cover all the four operations as below:

\author{
ST: Kafka Museum \\ 1- Kafka museum (transference) \\ 2- كافكا ميوز يم ('Kafka museyum') (substitution/transliteration) \\ 3- متحف كافكا ('the museum of Kafka') (translation proper) \\ 4- المتحف الشهير كافكا مافكا ('the famous museum of Kafka') (modification)
}


The diagram below explains the classification of the model clearly.

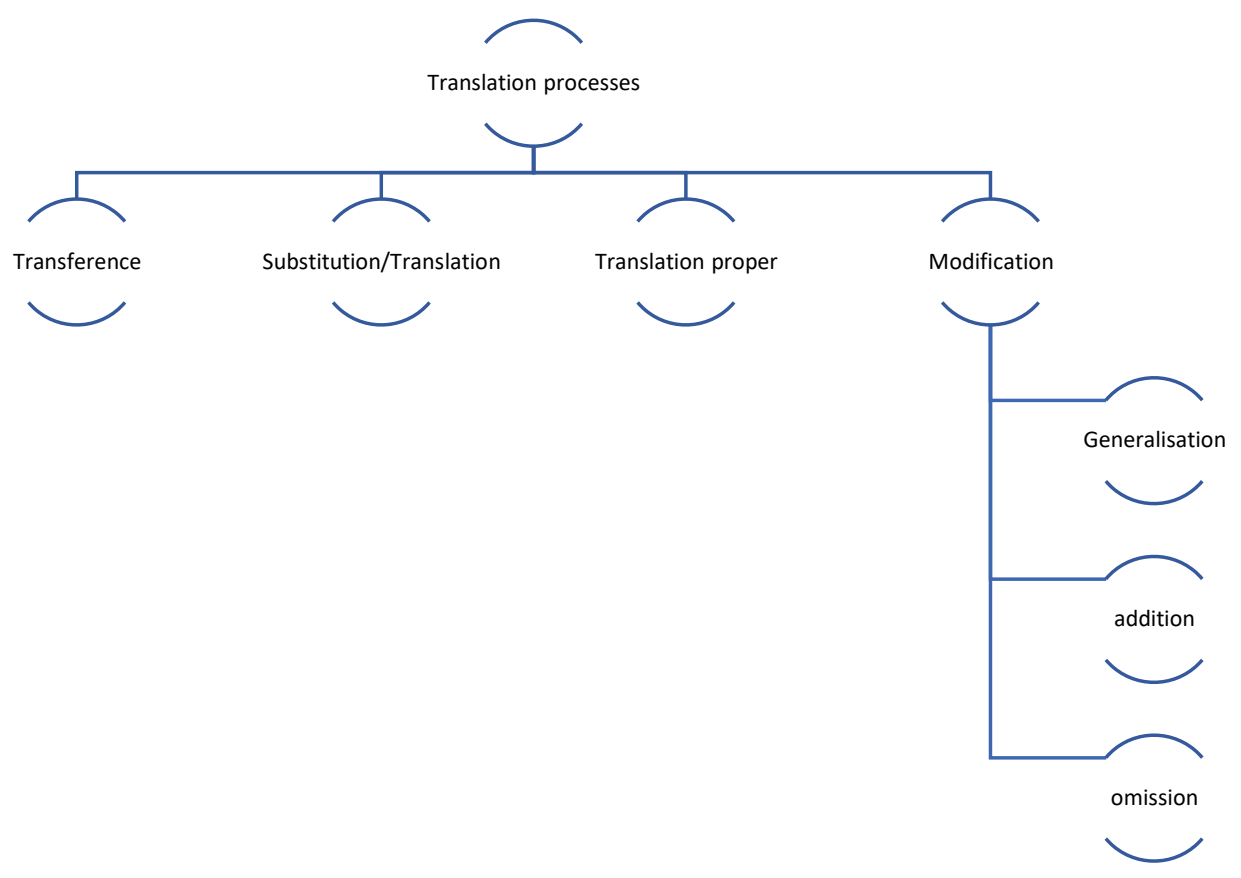

Figure 1: Vermes's model of operations for translating proper names (Vermes, 2003)

The list of collected terms from the data will exclude extremely common geographical names, such as 'India' الهند and 'Muscat' مسقط, which have fixed forms in both English and Arabic. Given their commonness, and the predictability of their TT equivalents, they are better to be excluded from the discussion of the translation of names. Moreover, not all of the previous examples illustrating Vermes's model are taken from the current data, but they are, rather, added from external resources to clarify the exact categorization based on the language pair of the study.

In this research the notion of 'transference' will be slightly developed to suit the current research data. The data shows several occurrences of transference, but they are all accompanied by an addition in the TT writing system. Therefore, transference will be also considered even though there is an addition because the ST writing system is being used and the analysis will investigate the involvement of these Latin-script forms in the Arabic text.

\section{4- Results and Discussion \\ 4.1 People's names}

The data shows only one example of transference in translating people names. This is in Article 23 page 43, where an Arabic ST presents two people names as follows: 'بوب فيشر 'Bobby Fischer' and 'بوريس سباسكي Boris Spassky'. In the English TT, these are rendered as 'Bobby Fischer' and 'Boris Spassky'. There is no clear explanation for the use of transference here especially when we find that other people names in the same article are translated using other processes. The majority of people's names are translated using two processes. The first of these is substitution, which is the one that is expected. People names usually have no meaning, which in turn explains this as the main way of translating this type. For instance, ST 'Lionel Messi' becomes TT ليونيل ميسي (Article 13, page 55) and ST وديع الصافي Arabic form is left for the translator to decide. This is shown by one example from the data where the same people name has been transliterated differently in Arabic on two different occasions. In Article 18 page 145, 'William' is rendered into Arabic as وليام However, in Article 27 page 70, 'William' is rendered in the TT as.

The second standard process for translating people names is translation proper. This is used especially either when the name, or part of it, has a meaning or when there exists a conventional equivalent of the ST name in the TT. In Article27, page 65, for example, 'Spider Man' has been translated as الرجل العنكبوت [lit: spider man] because of the two reasons above. However, this does not mean that the translator has not got the choice to use substitution, to give سبايدر مان, which is quite frequently seen in similar texts. Translation proper, however, is preferable as it adds to the TT meaning. In addition, the data demonstrates that titles accompanying names of people are usually translated. For instance, ST الإمبراطور وو تي is partly translated in the TT as 'Emperor Wu ti' to clarify the meaning of the title (Article 23, page 43), while ST 'King Abdullah' (Article 31, page 40) is translated 
as TT الملك عبدالله is أمير الشعراء أحمد شوقي Translation proper is also used to translate epithets, as when ST translated as 'the prince of poets Ahmed Shawki' (Article 24, page 53).

Modification is less frequently used in this category than translation proper. Only ten people names are translated using this technique, and almost every example involves changing the name with various different shades of modification being used. Thus, Arabic ST آلبرت becomes 'Albert Counties' (Article 25, page 27), where the translator finds it necessary to provide the full name in the TT for informative purposes. This contrasts with ST readers, who it can be assumed are fully aware of this name without writing it in full. Likewise, ST 'Sheikh Mansour' is modified to become TT الشيخ منصور بن زايد آل نهيان (Article 13, page 55). This addition is related to the fact that people with high-ranking titles in Arab society typically have their name given in full as a matter of respect. Another somewhat different example of modification is English ST 'King Odysseus' being rendered as (Article 20, page 43). The title 'King' is translated as البطل أوديسيوس [lit: the hero], which is regarded as an amendment of the proper name with a functional equivalent in the TT. Deletion is also used in the data as a type of modification. For example, the Arabic proper nameالشيخ بدر الدين أحمد بن محمد الصاحب الفقيه الشافعي [lit: Al Shaikh Bader Al Din Ahmed bin Muhammad Al Saheb Al Fagieh Al Shafi] is reduced to 'Imam Muhammad ibn Idris Al Shafi' (Article 23, page 42). Here 'Sheikh' has been replaced by 'Imam' and 'Idris' is added as the full formal name of this figure. Other examples of deletion involve removal of the epithet from the proper name. Thus, ST الفاروق عمر بن الخطاب becomes TT 'Omar ibn Al-Khattab' (Article 24, page 59). Parts of the ST name are removed in the TT particularly when the ST name is complex. Thus, for examples, خمارويه بن أحمد بن طولون is rendered into the TT as 'Ahmad Ibn Tulun'. In both the previous examples, the translator decides to delete elements of the ST name for reasons which might have to do with the size of the TT, since English texts usually takes more space than their Arabic counterparts. Alternatively, the translator may have chosen to give the minimum form which he or she felt to be appropriate for TT readers to comprehend without giving them too much unneeded information.

In summary, substitution/transliteration is the main technique used in translating people names in both directions, English to Arabic and Arabic to English. This is followed by translation proper in cases where the name, or a part of it, has a meaning. In a few cases, the translator might need to add or remove a portion of a complex people name, giving rise to modification. Lastly, transference is not a preferred choice for the translation of people names: the data records only one example of transference.

\subsection{Names of objects}

Names of objects constitute a high proportion of proper names covering all other names that are not people or geographical names. Starting with the first process, transference, the data shows ten examples where the names of objects are kept using English (Latin) script only in both texts, and interestingly in both directions. Thus, no Arabic script forms appear in any English texts that uses this process in the data. In one example, ST 'Beach Culture WLL' is translated as TT 'Beach Culture WLL مؤسسة' (Article 14, page 67), while the Arabic ST 'The Dark Horse فيلم' is translated into the English TT as 'The Dark House' (Article 23, page 43). One possible reason for using this process is that the translator may be assuming that TT readers have a basic knowledge of what the English object names refer to. Thus, it is easier to retain the English form in the Arabic TT for quick recall. Twenty-nine names of objects have been translated using substitution, though this is still less than the frequency of substitution for people's names. Names of famous places or tourist attractions form a large proportion of the examples. From English to Arabic, there is 'Stari Grad', which becomes ستاري غراد (Article 30, page 30) and 'Darat Al-funun', which is substituted by دارة الفنون (Article 31, page 41). This latter example is of Arabic origin because the text is describing a place in an Arab-speaking country. In contrast, سوق مجنة and are Arabic examples that become 'souq Okas' and 'souk Majannah' respectively (Article 26, page 63). Brand names are also found under this category, perhaps for the sake of keeping a similar pronunciation in both languages. 'Dolce \& Gabbana' is rendered as دولتشي آند غابانا (Article 19, page 49). The English (originally French) brand name فان كليف آند أربلز is also found in the Arabic text and is restored in the English TT to its original Latin-script form, 'Van Cleef \& Arples' (Article 25, page 23). One interesting trend in substitution that occurs on numerous occasions involves the translator using an 'amended' word order to accommodate the structure of the TL while keeping substitution. For instance, 'the Haram Masjid' is a name of a sacred place that is restored to its original Arabic form in the process of English-Arabic translation as (Article 9, page 31). The word order is different in the ST and TT, conforming to standard noun-adjective orders in English and Arabic. In English, an attributive adjective standardly comes before the noun, while in Arabic, it standardly comes after the noun. Likewise the English compound noun phrase (with also an attributive adjective 'Turkish'), 'Al-pasha Turkish Hammam' is rendered as the genitive structure حمام الباشا التركي [Hammam Al-pasha Al-turki] (with the attributive adjective التركي modifying the entire genitive structure حمام الباشا: (Article 31, page 43).

Translation proper is the most common procedure for translating names of objects. An analysis of the examples reveals that the majority of them involve a similar method whereby the name itself is substituted but the 'classifier' of the name is translated literally, whether the name has a meaning or not. Dickins et al. explain this characteristic in the case of English to Arabic 
translation. They provide a clear example where the ST name حديقة الهايد بارك" [lit: 'the park of Hyde Park'] is translated as TT: 'Hyde Park'. "The Arabic has a 'classifier' حديقة ['park'], which is there for stylistic reasons, and also to explain to the reader that this is a park. 'Hyde Park' is very well known in Britain, and the fact that it is a park is evident from its name. There is therefore no need for a separate translation for حديقة" (Dickins, Hervey and Higgins 2017b, pp. 85-86; p. 129).

As for the data, the first example is 'Vintage rides company', which becomes شركة فينتاج رايدس (Article , page 17). Here 'company' is translated literally into Arabic but the name of the company is transliterated even though these is an equivalent in the TT. The same approach is usually found in the names of dishes, markets and places that are unique to certain cultures such as the translation of 'Tailing Chan market' (Article 5, page 36) and 'Shahi ras pacan pitha dish' (Article 11, page 59) as سوق تالينج respectively. Examples of this are also found in Arabic-English texts as in السفية شاهي راس باكان بيثالand for 'Ship تشان Dara' (Article 22, page 87). However, on a few occasions, the majority of the name is translated literally as in ST 'The IMG Worlds of adventure theme park', which becomes TT منتزه آي أم جي عالم من المغامرات (Article 7, page 26). This also occurs in Arabic-toEnglish translation, as in كتاب رسول الله وخاتم النبيين- دين ودولة wich is a name of a book. This is literally translated as a whole as 'Messenger of Allah and the Seal of the Prophets - religion and state book' (Article 26, page 56).

The last process, modification, involves the highest proportion of examples of all names with 44 occurrences in the data. Most of these are either addition or omission. Addition usually involves adding one or two words that work as classifiers to categorise the name in the TT. For instance, 'Legoland Dubai' is rendered as حديقة ليجو لاند دبي (Article 7, page 28). The word حديقة [park] is added to clarify (classify) what kind of thing ليجو لاند دبي is. In contract, omission is usually used in cases where it is better to delete the explanatory word that follows or precedes the name because TT readers already have background knowledge about the name. For example, 'Dul Hijjah, month in Islamic calendar' becomes شهر ذي الحجة (Article 9, page 31). As the TT in the previous example is Arabic, the name of the month is without doubt a known term in Islamic culture and there is thus no need to explain it. A few other applications of modification involve generalisation as well. In one example, 'FC Barcelona' is translated as نادي برشلونة (Article 13, page 55), where FC stands for football club, but only 'club' is translated (as نادي) without specifying the club's category.

In summary, translation proper is the main process used to translate names of objects. Interestingly, modification is the most common alternative to translation proper in case the name needs more clarification or a small change to take TT readers' knowledge into account. Although substitution is also used for names of object, the limited number of examples reflectd the fact that it is only used when the name is well known in the target culture. Transference, as expected, is the least preferred choice for translating the names of objects and is restricted to a few names that are recognized by Arabic target readers in their Latin-script form.

\subsection{Geographical terms}

The last category of names covers any term that is related to geographical elements such as cities, villages, roads, beaches, valleys, etc. They are regarded as the most straightforward type of terms when it comes to translation because they rarely have a connotative meaning. Abdolmaleki (2012, p. 843) states that geographical names are in general a less challenging type in translation than other names as they usually carry no meaning. He also mentions that unknown geographical names in particular should be accompanied by a classifier to achieve the best equivalence (ibid). It should be noted that several tourist attraction locations are also included in this category because they have become well known in their cities and countries such as 'Kafka museum' and 'Silver beach'. The data has so far supported this claim as well-known countries and cities like 'India' الهند and 'Muscat' مسقط do not need classifiers. Thus, known geographical names are removed from the research sample because they have their own fixed forms, as explained above.

In the data, there is not a single use of transference to translate geographical terms, which is a quite striking result. All geographical names are rendered using the Arabic alphabet in the TT, which might reflect that the translator prefers the situation of being able to read the name easily over solely counting on the TT readers' background knowledge.

Substitution and translation proper are the commonest procedures for translating geographical terms with 77 and 72 terms, respectively. One interesting example of substitution is 'Wadi Darbat', which becomes وادي دربات (Article 2, Page 24). Noting that the ST is written in English about Oman, and that 'Wadi' means 'Valley', we can see that the translator keeps the Arabic equivalent (classifier of the term) in the ST. This approach is repeated many times in Arabic-English substitution but does not appear in the opposite direction (English-Arabic). Again, this supports the idea of keeping the ST term with its classifier in the TT to reflect the fact that reproducing the whole term is sometimes more important than understanding the Arabic meaning. All examples under English-to-Arabic geographical substitution are single names with no classifier as in 'Shiraz', which is rendered as شيراز (Article 29, Page 23). The Arabic-to-English data has also several occurrences of names of less known places with no classifier as in البصرة and وادي الباطن, which are translated as 'Al-Basra' and 'Wadi Albatin (Article 24, Page 59). 
Translation proper is the second most common procedure for geographical terms as indicated earlier, most of them being translated with a classifier. For instance, the Arabic-origin term 'Al Mughasayl beach' becomes شاطئ المغسيل (Article 2, Page 24) while the English term 'Little Venice town' becomes قرية ليتل فينيس (Article 35, Page 16). However, in some of the examples of geographical terms, the names do have a meaning, but they are transliterated in the TT without alteration. For instance, 'Paradise beach' is translated as شاطنئ بارادايس (Article 20, Page 43). The translator here has another choice, to translate 'Paradise' as الفردوس, but he/she finds that it is more important to render the exact name losing some of the ST connotations in the process. By contrast, a few other examples do involve translating the whole names as they have a meaning, such as 'Flea markets', which becomes 'أسواق البراغيث (Article 12, Page 19), where it might be found better to deliver the meaning over rendering the foreign name for TT readers.

In the absence of transference under this category, modification has the least number of uses with twenty-eight occurrences. Addition and omission are the most noticeably used processes under modification. Examples of addition usually contain an added classifier for the geographical term. In one of the English-Arabic translation examples, the name 'Rajastan' becomes [اجستان [lit: Rajastan state] (Article 1, Page 19), while in an Arabic-English text, سرسق is rendered to 'Sursock neighbourhood' (Article 8, Page 21).

As for omission, the classifier or part of it may be removed for reasons related to the clarity of that term in the TT without a classifier or simply to remove any additional details which are unimportant for TT readers. For instance, 'Aghartha jazz club' becomes نادي أغارتا [lit: Aghartha club] (Article 12, Page 19). Generalization also appears in geographical terms in two instances. In one example, 'The valley of Mina' becomes مشعر منى (Article 9, Page 31), where the term is originally Arabic, but it is used in the English ST. Here, the English text gives a general meaning for مشعر مشع 'valley' instead of translating it as 'holy site', which would give a more denotatively equivalent meaning. This usage may reflect the intended TT readers who are believed to be aware of the term.

In brief, as with people's names, substitution is the most frequently used process with geographical names. Translation proper is also common as the term's classifier needs to be translated. Modification is only used in limited situations when the term becomes clearer by using addition, omission or generalization. Finally, transference is not used in this section: there is no single example under geographical terms.

Overall, people's names involve the highest number of substitutions while the most frequently occurring operation for names of objects is translation proper. Looking at the total number of occurrences of each translation operation, substitution is the most frequent translation procedure for translation of names with around 307 examples. Translation proper has a total of 269 occurrences. Modification and transference have fewer occurrences, the total number of examples of modification being 82 for all types of names, while there are only 11 occurrences of transference, this being a rare translation operation in this study. Figure 2 presents the total number of occurrences of the four translation operations for each type of proper names.

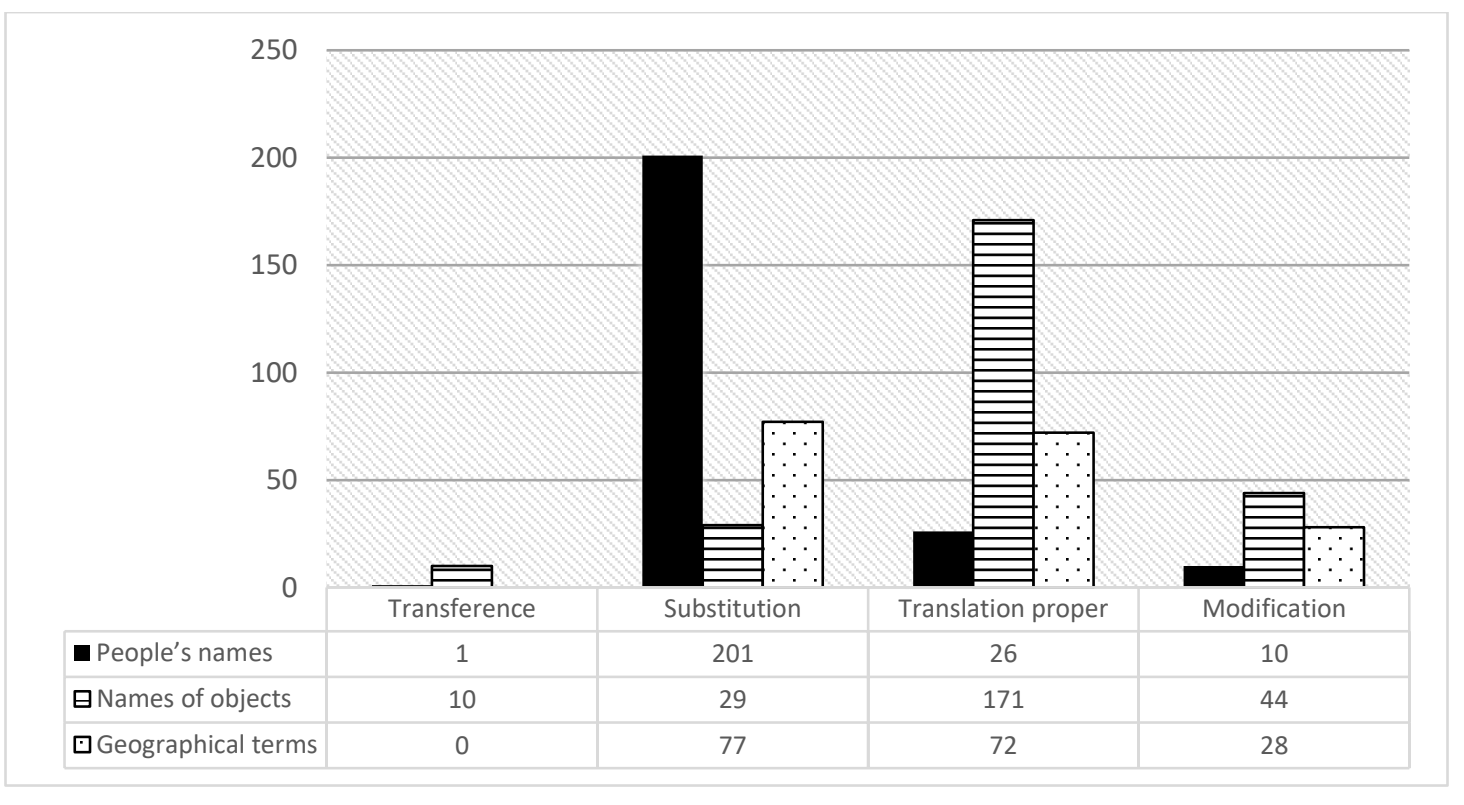

Figure 2: Results of translation operation occurrences for each type of translation of names 


\section{Conclusion}

The present study aims at investigating the use of translation operations for rendering proper names in consumer-oriented texts. the Proper names in the data were first categorised according to Newmark's categorization of proper names (1988), i.e. people's names, names of objects and geographical terms. Vermes's model of translation 'operations' for proper names (2003) was adopted to determine the type of translation used. The data shows that all four of Vermes's operations for the translation of names are used indeed in the data articles, namely: transference, substitution/transliteration, translation proper and modification. The results show that both substitutions and translation proper are common procedures in the data, suggesting an attempt on the part of the translators to make the translation product as clear and accurate as possible. Modification and transference are confined to cases where the proper name needs more clarification for TT readers, or where it is likely to recognizable in the ST form for TT readers.

The study has developed a framework for analysing tendencies in translation of names between English and Arabic. Although it proved impossible in this paper to contact translators or editors working in the chosen in-flight magazines for them to elaborate on the translation processes used, this would be an interesting way in future studies to investigate publishers' translation policies and parameters. The areas of investigation could also cover transediting procedures, motivations for translation choices and restrictions, and any other factors that have a crucial influence on the translation product.

Funding: This research received no external funding"

Acknowledgement: I would like to express my very great appreciation to my PhD supervisor, Professor James Dickins, for his valuable and constructive suggestions of this research work. His willingness to give his time so generously has been very much appreciated.

Conflicts of Interest: The author declares no conflict of interest.

\section{References}

[1] Abdolmaleki, S. (2012). Proper Names in Translation: An Explanatory Attempt. The Social Sciences, 7, $832-837$. http:/doi:10.3923/sscience.2012.832.837

[2] Dickins, J., Hervey, S.G.J. \& Higgins, I. (2017). Thinking Arabic translation (2nd edn.). Routledge.

[3] Fernandes, L. (2006). Translation of Names in Children's Fantasy Literature: Bringing the Young Reader into Play. New Voices in Translation Studies, 2(2), 44-57.

[4] Hermans, T. (1988). On translating proper names, with reference to De Witte and Max Havelaar. In M. J. Wintle (Ed.) Modern Dutch Studies. Essays in Honour of Professor Peter King on the Occasion of his Retirement. London/Atlantic Highlands: The Athlone Press.

[5] Newmark, P. (1988). A Textbook of translation. Prentice Hall.

[6] Nord, C. (2003). Proper names in translations for children: Alice in wonderland as a case in point. Meta: Translators' Journal, 48(1-2), 182196.

[7] Schaffner, C. (2011). Functionalist approaches. In M. Baker, \& G. Saldanha (Eds.), Routledge encyclopedia of translation studies. Routledge.

[8] Vermes, A. P. (2003). Proper names in translation: An explanatory attempt. Across Languages and Cultures, 4(1), 89-108. http://dx.doi.org/10.1556/Acr.4.2003.1.5 